\title{
Las aspiraciones marítimas de Bolivia: antes y después de Cochabamba
}

\author{
Jaime Lagos Erazo*
}

\section{PALABRAS PRELIMINARES}

Al escribir este ensayo no es nuestra intención remover el pasado para ingresar en el poco fértil terreno del debate sobre los títulos históricos que tanto Chile como Bolivia argumentan para fundamentar, en el caso de nuestro país, sus derecho territoriales que, tras varias tratativas previas, derivan en el Tratado de Paz y Amistad de 1904 y, en el caso de Bolivia, de sus pretendidos derechos históricos calificados como "expectaticios» para dar sustento a su «aspiración marítima» de tener un acceso soberano al Océano Pacífico. Tampoco nos remontaremos a las causas y secuelas de la Guerra del Pacífico que entre 1879. 1884 enfrentó Chile a Bolivia (y Perú), como resultado de la cual se convino

* Profesor de la Facultad de Derecho de la Universidad de Chile; ex embajador, ex Director Jurídico de la Cancillería chilena; autor de varias obras y artículos sobre los temas vecinales. ese acuerdo que fijó definitivamente los límites entre los dos países.

Al respecto, en su excelente obra "Chile y Bolivia. Un largo camino de la Independencia a Monterrey» el ex embajador Carlos Bustos se pregunta con razón "¿para qué escarbar el pasado que «se presenta en forma distinta y en que se han creado mitos casi imposibles de destruir- más cerca estaremos de entendimientos realistas, acordes con el siglo XXI?» ${ }^{1}$

Tampoco pretendemos hacer un recuento de las múltiples instancias en que los dos gobiernos han dialogado para encontrar un camino de entendimiento en esta compleja cuestión, salvo para referirse a algunas oportunidades más recientes, que sirven para colocar este relato en su actual contexto histórico. ${ }^{2}$

1 RIL Editores, Santiago 2004.

2 Figueroa Pla, Uldaricio (1992), La demanda marítima boliviana en los foros 
Lo que nos lleva a volver sobre estos temas es sobre todo el hecho de que el 23 marzo de 2010, el Presidente de Bolivia, Evo Morales, tomó la iniciativa de dar un vuelco fundamental en la estrategia en favor del diálogo que su gobierno estaba incursionando en sus relaciones con el nuestro desde los años 2000, con un encendido discurso que hizo revivir los hechos del pasado con una serie de tergiversaciones históricas, amenazas y presiones.

El retorno de la democracia en Chile y el arribo al poder en Bolivia de Evo Morales, Jefe de Estado que gozaba de amplio respaldo popular, fueron buenos indicios para esperar que ambos países se encaminaban a superar el periodo de recriminaciones y tensiones y comenzar un diálogo bilateral productivo en el extenso y tormentoso decurso de incomprensiones y frustraciones en nuestras relaciones vecinales. ${ }^{3}$

internacionales, santiago,Editorial Andrés Bello.

3 Walter Guevara Arce, ex canciller de Bolivia, destaca cuatro de las que denomina « oportunidades perdidas», en que Chile y Bolivia estuvieron cerca de encontrar una solución al problema marítimo de su país: las gestiones de 1895; las notas de 1950; las negociaciones de Charaña (1975-1978) entre Banzer y Pinochet y las gestiones Bedregal-Del Valle de 1987. En verdad, ha habido muchas más, oficiales y oficiosas, siendo una de las más importantes las celebradas por el Presidente Lagos desde el año 2000 con varios Mandatarios bolivianos que se caracterizaron como las negociaciones "gas por mar». A todas ellas se refieren en forma detallada las obras de Carlos Bustos y Uldaricio Figueroa, antes identificadas.
Por desgracia, este vaticinio no se cumplió cabalmente y prosiguieron diversas etapas marcadas por permanentes altibajos. En las actuales circunstancias en que la parte boliviana pretende inclusive «dar por muerto al Tratado de 1904» no podemos eludir referirnos, aunque sea de manera sumaria, a algunas de las citadas tergiversaciones históricas y jurídicas que fundamentan la presente posición del gobierno del Presidente Morales en sus vinculaciones con Chile.

Esas distorsiones volvieron a repetirse durante y después del recién concluido $42^{\circ}$ período de sesiones de la Asamblea General de la OEA, celebrado en Cochabamba del 3 al 5 de junio pasado, que marcó una inflexión aún más negativa de parte de Bolivia hacia Chile, paralizando los avances logrados hasta ahora.

En resumen, lo que podría haber sido el «comienzo del fin» de un extenso proceso de diálogos y negociaciones en torno a la llamada «causa marítima boliviana» ha vuelto a transformarse en fuente de aguda fricción, de contornos inciertos, al resucitar nuestro vecino del noreste todos los ingredientes que desde hace más de un siglo siguen envenenando sus relaciones con Chile, con el que comparte una frontera común de más de $880 \mathrm{Km}$. y con el cual todavía no tiene vínculos diplomáticos normales, interrumpidos ya dos veces( 1962 y 1978).

Con sus actuales planteamientos, es difícil si no imposible encontrar en la historia contemporánea otro ejemplo de una nación como Bolivia que proclama ahora la necesidad de revisar e 
incluso desahuciar, un tratado de límites concluido con Chile hace más de un siglo, con argumentos tan falaces como que fue objeto de un «tratado injusto», "impuesto por la fuerza", que "perjudica su desarrollo", que " provoca su enclaustramiento", por efecto del cual nuestro país « usurpó a Bolivia un litoral de $400 \mathrm{Km}$. y un territorio costero de más 120 mil Km2», etc. A ellos se ha venido a agregar una nueva acusación: que Chile ha dejado de cumplir con las obligaciones de libre tránsito convenidas por el Tratado de Paz y Amistad de 1904 y diversos convenios complementarios en favor de Bolivia.

En un artículo de opinión como el presente ciertamente no es posible abarcar todo el extenso recorrido de las relaciones históricas entre Chile y Bolivia, estudiado por tantos analistas e historiadores chilenos, ${ }^{4}$ pero sí, al menos proporcionar una visión más actualizada de la presente situación, teniendo como eje central lo sucedido en la última Asamblea General de la Organización de los Estados Americanos celebrada en Cochabamba y sus eventuales consecuencias en caso de que Bolivia prosiga el equivocado camino de continuar llevando sus aspiraciones

$4 \quad$ Las obras más completas en este sentido además de las mencionadas son las publicadas por Guillermo Lagos C., Historia de las Fronteras de Chile. Los Tratados de Limites con Bolivia, Editorial Andrés Bello 1981; Santiago Benadava, Historia de las Fronteras de Chile, Editorial Universitaria, 1993 y Jaime Eyzaguirre, Breve Historia de las Fronteras de Chile, Editorial Universitaria, 1966. marítimas por la vía multilateral, abandonando el diálogo bilateral reclamado por todas las naciones del Continente.

\section{PARTE PRIMERA \\ ¿HACIA EL TÉRMINO DEL DIÁLOGO BILATERAL?}

Para comprender mejor el tema, primero dejemos hablar al actual Presidente de Bolivia, Evo Morales, resumiendo algunas de las reivindicaciones bolivianas que ha esbozado, conduciendo a su país a un nuevo y más peligroso intento por internacionalizar e inclusive judicializar sus aspiraciones marítimas.

\subsection{Párrafos destacados del discurso} pronunciado por el presidente de Bolivia, Evo Morales, en el Día del Mar

(23 de marzo de 2011, conmemoración del $132^{\circ}$ aniversario de la "pérdida del litoral boliviano" tras una guerra con Chile). ${ }^{5}$

«Volver la mirada atrás, es encontrarnos con una realidad que hoy día debemos recordarla y explicarla para poder enmendar la injusticia de este enclaustramiento.

Bolivia nació con su litoral soberano en el Océano Pacífico....

Eduardo Avaroa, convertido en el héroe nacional de Bolivia después de la defensa del puente de Topater, antes del ingreso de las tropas chilenas en Calama, en una de las primeras batallas de la Guerra del Pacífico, en la cual perdió su vida. 
Como consecuencia de la guerra, el país vio cercenado su territorio y su acceso soberano al Océano Pacífico...

El Tratado de 1904 se forjó bajo la presión chilena y la fuerza....

El injusto Tratado de 1904, no se cumple ni ha sido cumplido por Chile. El régimen de libre tránsito no sólo fue afectado por la privatización de los puertos que utiliza Bolivia, sino que no funciona como debería.

Bolivia recibió múltiples muestras de apoyo en diversos foros y encuentros internacionales...

En nuestra gestión logramos iniciar un diálogo bilateral entre Bolivia y Chile, sin exclusiones sobre trece puntos entre los que se encuentra el tema del mar. Gracias a este diálogo se ha logrado la sensibilización en diferentes estamentos de parte de la población de Chile....

El Derecho Internacional, en estas últimas décadas y particularmente estos últimos años, ha dado grandes avances, ahora existen tribunales y cortes a los cuales pueden llegar ${ }^{6}$ los Estados soberanos a reclamar y demandarlo.

6 Mencionó también la nueva Constitución boliviana aprobada en 2009, que en su art.267, bajo el título «Reivindicación Marítima» establece que: 1. El Estado boliviano declara su derecho irrenunciable e imprescriptible sobre el territorio que le dé acceso al Océano Pacífico y su espacio marítimo». Luego en el art. noveno transitorio señala que " los tratados internacionales anteriores a la Constitución y que no la contradigan se mantendrán en el orden jurídico interno, con rango de ley. En el plazo de cuatro años desde la elección del nuevo Órgano ejecutivo, éste
La comunidad internacional debe entender ahora que ha llegado el momento, para que esta inmensa herida que tenemos los bolivianos por nuestro enclaustramiento marítimo sea cerrada en base a un proceso de connotaciones históricas que con un fallo justo y certero, le devuelva la cualidad marítima a nuestro país».

\subsection{Respuesta del Presidente Piñera}

El 24 de marzo de 2011, el Presidente Sebastián Piñera aseveró que «las declaraciones del Presidente Morales incluyendo su intención de acudir ante tribunales u organismos internacionales para su aspiración reivindicatoria territorial y marítima constituyen un serio obstáculo para las relaciones entre ambos países y no se condicen ni con la letra ni con el espíritu del Tratado de 1904».

Enfatizó luego que los dichos de Morales se contraponen a "los términos acordados en los múltiples encuentros de trabajo»y "comprometen el acuerdo alcanzado en diciembre pasado entre los presidentes de Chile y Bolivia para reforzar las relaciones bilaterales». Agregó que «Bolivia no puede pretender un diálogo directo, franco y sincero como sostuvo el Presidente Morales en su discurso, mientras simultáneamente manifiesta su intención de acudir a tribunales u organis-

denunciará y, en su caso, renegociará los tratados internacionales que sean contrarios a la Constitución». Obvia referencia al Tratado de 1904. 
JAIme LAgos Erazo • Las aspiraciones marítimas de Bolivia...

mos internacionales para impugnar un tratado plenamente vigente».

Asimismo, la prensa chilena conjeturó que «de esta forma, La Moneda fijó que, a partir de ayer, las relaciones Santiago-La Paz no serán fluidas o, al menos, no al nivel alcanzado en el último año. El anuncio de Morales resquebraja las medidas de confianza impulsadas por ambos gobiernos para acercar posiciones que permitieran llegar a un consenso en la llamada agenda de 13 puntos.»

El Presidente Piñera recordó también que Chile no tiene temas pendientes con Bolivia, pues todo quedó zanjado en el tratado de 1904, ratificado por el país altiplánico y por ende, la «multilateralización» de la pretensión boliviana solo entrampará los posibles avances, ya que Chile está dispuesto a conversar solo sobre la base de encuentros bilaterales. Por otro lado, el Presidente Piñera reiteró la «voluntad de diálogo bilateral para seguir avanzando en la búsqueda de soluciones concretas, útiles y factibles para ambos países», conforme al diálogo bilateral que había continuado desde que asumió el poder en marzo del 2010.

Cabe recordar que en plena campaña presidencial, Piñera dijo que no estaba disponible para cesiones de soberanía, manifestándose sí dispuesto a continuar dicho diálogo bilateral para facilitar el acceso del tránsito boliviano por los puertos chilenos. Inicialmente, Bolivia, a través de sus más altos personeros, inclusive Morales en una extensa entrevista en el diario «El Mercurio», reconoció «que un problema de tantos años no se podía resolver en tan corto tiempo" y elogió el diálogo bilateral entablado con Chile, puntualizando que "no creía tanto» en la instancia judicial internacional.

Como se dijo, durante la administración del Presidente Piñera continuaron las consultas políticas entre los vicecancilleres de ambos países bajo una agenda «flexible» de 13 puntos convenida el año 2001 por los entonces cancilleres en la cumbre de Algarve. Ello había permitido iniciar negociaciones en 2006 sobre una serie de materias de interés común, entre ellas los controvertidos asuntos del «tema marítimo (punto 6) y el aprovechamiento de las aguas del río Silala (tema 13), casi en todos los casos en favor de Bolivia, lográndose tangibles resultados en algunas áreas.

En cuanto al tema marítimo, en la primera reunión de ese mecanismo realizada durante el gobierno de Piñera convinieron en concretar propuestas «concretas, factibles y útiles», dejando en suspenso el tema del aprovechamiento de las aguas del río Silala, otra de las materias más contenciosas.

Cabe recordar que ya en septiembre de 2009 el Presidente Morales, en el primer emplazamiento público al gobierno de la ex Presidenta Bachelet, había declarado que su país «espera una propuesta del gobierno chileno sobre la salida al mar para que prosigan las negociaciones». Días más tarde, el entonces canciller chileno, Mariano Fernández, había explicado que el go- 
bierno de Bachelet no había accedido a discutir soberanía y menos aún al norte de Arica. Añadió que la solución y posibilidades son «recintos o lugares que sean accesibles para Bolivia y aceptables para un acceso al mar». Precisó que se estaba en una construcción teórica y que no se habían propuesto lugares específicos, aunque después hubo varios trascendidos respecto de estas conversaciones, las que se han mantenido oficialmente en reserva.

\subsection{Nuevo deterioro de las relaciones bilaterales}

Desde el discurso del 23 de marzo de 2011 en que el Presidente Morales anunció la judicialización del tema marítimo boliviano, su comportamiento siguió un curso totalmente errático frente a Chile, a veces profiriendo amenazas y en otras haciendo ofrecimientos conciliatorios en pro de continuar conversando sobre dicho tema incluido en la agenda de 13 puntos, negociaciones que el gobierno de Piñera congeló después de la mencionada intervención boliviana.

Desde entonces, Morales siempre dejó abierta la posibilidad de que su país obtenga acceso soberano al mar por la vía multilateral o el diálogo, no obstante claras advertencias del gobierno del Presidente Piñera de que ambos caminos eras incompatibles y de que nuestro país se oponía a toda cesión de soberanía. Por lo demás, diversas encuestas de opinión celebradas en Chile favorecían ampliamente esta tesis, más aún si ello significaba cortar en dos el territorio nacional.

Nuestro Primer Mandatario también reiteró que la ya mencionada Constitución boliviana de 2009 que debiera conducir en 2013 a una revisión unilateral del Tratado de 1904 constituía un elemento inaceptable para nuestro país debido a que desafiaba el derecho internacional. Durante el gobierno de la Presidenta Bachelet, Chile había protestado y formulado una reserva a ese texto constitucional.

No obstante estas amenazas siempre latentes, Chile dejó en evidencia su voluntad de continuar ampliando las facilidades de libre tránsito que concede a Bolivia por su territorio ${ }^{7}$ al invertir cuantiosas sumas para rehabilitar el Ferrocarril de Arica a La Paz y las vías terrestres al país del Altiplano, como también mejorar los puertos asignados al comercio con Bolivia. Así lo pudo comprobar in situ una comisión parlamentaria chilena. Con ello nuestro gobierno buscaba no dar ningún pretexto a Bolivia de que había dejado de cumplir sus obligaciones de tránsito (y acuerdos posteriores) derivados del Tratado de 1904, cuestión que en el último tiempo ha sido una acusación boliviana muy recurrente.

Entretanto, el contacto bilateral ha seguido abierto. Como es natural, la vecindad territorial necesariamente ha creado múltiples oportunidades de contacto entre las autoridades de ambos países, lo que se manifiesta día a día

A esta materia nos referimos con mayor detalle en páginas $25 \mathrm{y}, 26$. 
JaIme Lagos Erazo • Las aspiraciones marítimas de Bolivia...

(comité integrado de fronteras, reposición y densificación de hitos, controles policiales, devolución de automóviles robados, contrabando, drogas, etc.)

\section{PARTE SEGUNDA}

\section{INTERNACIONALIZACIÓN}

\section{DEL TEMA}

\subsection{Bolivia recurre a los foros internacionales}

Los intentos bolivianos por llevar su «reivindicación marítima» a los foros internacionales tiene un largo historial de esfuerzos frustrados a los que no referimos brevemente a continuación.

Al poco tiempo (1910) de haberse suscrito y ratificado por los Congresos de ambos países el Tratado de Paz y Amistad de 1904, el gobierno boliviano comenzó a denunciar la pérdida de su litoral, calificándola de «despojo» y exigiendo a Chile un acceso soberano y propio al mar de lo que denominó su «litoral cautivo».

\subsubsection{La Sociedad de las Naciones (SDN)}

El primer intento de reivindicación se produjo en noviembre de 1920 en la Asamblea de la Sociedad (o Liga) de las Naciones (precursora de la actual Organización de las Naciones Unidas). La demanda boliviana se basó en el artículo 19 del Pacto de Versalles según el cual la
Asamblea podría invitar a los miembros de la Sociedad a proceder a un nuevo examen de los tratados que hubiesen dejado de ser aplicables, así como de las situaciones cuyo mantenimiento pudiera poner en peligro la paz del mundo. Según argumentó entonces Bolivia, el Tratado de 1904 había sido impuesto por la fuerza; Chile no cumplía algunas de sus disposiciones; había generado una amenaza permanente a la paz y Bolivia se había convertido en un país cerrado y privado de todo acceso al mar.

La solicitud boliviana fue inscrita fuera de plazo por lo que debió replantearse al año siguiente (1921).

Chile por cierto refutó esa argumentación recordando que el Tratado de 1904 fue suscrito sin compulsión alguna; que Chile lo cumplía fielmente; que nuestro país no abrigaba pensamiento alguno de recurrir a la guerra con Bolivia y que ese país había renunciado voluntariamente al territorio cedido a Chile. Enseguida, hizo valer varias objeciones formales respecto de la competencia del Organismo y reiteró que el sistema internacional «se desmoronaría el día en que se admitiera que un Estado tiene derecho a pedir la revisión de los tratados que ha suscrito-especialmente los de paz-contra la voluntad del otro».

La Asamblea nombró una comisión integrada por destacados juristas de la época para que emitiera una opinión sobre esta solicitud. Su conclusión fue tajante «la demanda de Bolivia es inadmisible, pues la asamblea de la SDN no puede modificar por sí misma ningún tratado; la modificación de los 
tratados es de la sola competencia de los Estados Contratantes». Entonces, cuando derrotada su moción el delegado boliviano Aramayo manifestó que su país se reservaba el derecho a replantear su demanda en una próxima sesión, el representante británico, el renombrado político Lord Balfour, que presidía la Asamblea, replicó que: «esperamos que esa eventualidad no se presentará y que este incidente no se renovará más».

\subsubsection{Las Naciones Unidas}

En la Conferencia de San Francisco (1945) que dio origen a la Carta de las Naciones Unidas, Bolivia intentó infructuosamente que ese instrumento no recogiera en el preámbulo una propuesta chilena sobre el respeto de los tratados, lo que quedó consignado en actas. Luego intentó que se incluyera una cláusula sobre la revisión de los tratados semejante a la contenida en la Carta de la SDN. Aunque en este esfuerzo fue respaldado por otros países, en definitiva prevaleció la tesis de que la Asamblea General de la Naciones Unidas podía formular recomendaciones para el arreglo pacífico de cualquier situación que perjudicara, inter alia, las relaciones amistosas entre las naciones, pero sin incluir la revisión de los tratados, como lo deseaba Bolivia.

Los intentos bolivianos habían fracasado nuevamente. Una vez más, muy pocos miembros de esos organismos mundiales estuvieron dispuestos a poner en entredicho los tratados de paz concluidos al término de las dos Guerras Mundiales.

A partir de 1962 Bolivia ha utilizado esporádicamente la Asamblea de las Naciones Unidas y otras instancias internacionales para plantear su reivindicación marítima, sin obtener resultados concretos y recibiendo adecuadas réplicas chilenas, que se han convertido a veces en un mero ritual de oratoria.

\subsubsection{El caso del río Lauca}

En los intentos bolivianos por llevar a los foros multilaterales sus aspiraciones marítimas tuvo especial relevancia el diferendo que se produjo en 1962 por el uso por Chile de las aguas del río Lauca, tema conexo que se prestaba para ese propósito.

Bolivia anunció entonces que denunciaría a Chile ante la OEA y ese año nuestro gobierno, bajo la presidencia de Jorge Alessandri, resolvió abrir las compuertas y utilizar las aguas. Ello condujo a un serio quebrantamiento de las relaciones bilaterales, que fueron suspendidas por Bolivia.

Finalmente, el Consejo de la OEA recomendó a las partes que acudieran a algún medio de solución pacífica. Bolivia, insatisfecha se retiró del Consejo. Desde entonces Chile ha continuado aprovechando sin menoscabo las aguas del río Lauca, aunque en conversaciones bilaterales recientes ha vuelto a reclamar por el uso chileno tanto de las aguas del Lauca como de otros recursos hídricos en el norte del país. 
JaIme Lagos Erazo • Las aspiraciones marítimas de Bolivia...

\subsubsection{Las resoluciones de la OEA}

Además de la intervención de la OEA en el caso del Lauca, entre 1979 y 1989 Bolivia procuró en once oportunidades involucrar a este foro interamericano en su demanda marítima, la que ha quedado inscrita a petición boliviana en la agenda de las reuniones anuales ( «problema marítimo de Bolivia») y anualmente conoce de un «informe» presentado por dicho país sobre la materia.

Cabe recordar que este periodo coincidió con la vigencia en nuestro país de un régimen dictatorial que no contaba con mayor apoyo en la región. A partir de 1990, al restablecerse la democracia el tema adquirió otra dimensión, aunque Bolivia no ha dejado de evocarlo en cada Asamblea General, sin obtener un pronunciamiento favorable a sus aspiraciones.

Uno de los momentos más álgidos se vivió en la Asamblea General de 1979 celebrada en La Paz, al cumplirse el centenario de la Guerra del Pacífico. Allí, en la resolución respectiva se incorporaron conceptos muy favorables a Bolivia tales como que "es de interés hemisférico permanente encontrar una solución equitativa por la cual Bolivia obtenga acceso soberano y útil al Océano Pacífico» y recomendar a los Estados concernidos a iniciar negociaciones encaminadas a dar a Bolivia «una conexión territorial libre y soberana con el Océano Pacífico", además de otras consideraciones.

\subsubsection{Bolivia renueva internacionalización del tema marítimo.}

Aunque este inconducente camino adoptado por Bolivia parecía abandonado, como lo anunció el Presidente Morales en su comentado discurso de 23 de marzo de 2011, su gobierno comenzó al poco tiempo a realizar diversas acciones para llevar la cuestión a los foros internacionales: creó una Secretaría de Reivindicación Marítima; hizo ratificar por el Parlamento el Pacto de Bogotá sobre Soluciones Pacíficas de 1948, con una reserva para poder acceder a la competencia de la Corte Internacional de Justicia de la Haya; contrató una comisión de juristas internacionales de prestigio para asesorarlo (Antonio Remiro Brotóns (España) y Marcelo Kohen (Argentina), entre otros); intentó introducirse por «la puerta trasera» en el diferendo marítimo que se ventila entre Perú y Chile ante la CIJ exponiendo en un documento sus conocidos y distorsionados puntos de vista sobre la mediterraneidad boliviana, sin solicitar intervenir como tercero en la disputa conforme al artículo 62 del Estatuto de la Corte. La Corte ni siquiera lo transmitió a las partes a través de sus agentes en La Haya, por lo cual es muy posible que no quede registrado en los documentos de la Corte: su Secretaría se limitó a comunicarlo a los gobiernos de las partes para su mera información; se anunció con gran publicidad que el Presidente Morales se presentaría personalmente en La Haya cuando en febrero de este 
año la Corte reanudara sus actividades anuales, para imponerse de «cómo funciona dicho tribunal», propósito que no cumplió de inmediato.

\subsubsection{Asamblea anual de la OEA de 2011}

El paso siguiente fue el intento boliviano de aprovechar nuevamente la Asamblea General de la OEA que se celebró en San Salvador en junio de 2011, para introducir una resolución en su favor cuando se examinara el tema marítimo de Bolivia.

En esa oportunidad, a través del canciller Choquehuanca, Bolivia intentó infructuosamente obtener que se ratificara la resolución de la OEA de 1979, provocando un áspero diálogo con el canciller Moreno. En su intervención amenazó nuevamente con acudir a las instancias jurídicas internacionales para obtener el anhelado acceso al Océano Pacífico; por no haber reconstruido Chile el ferrocarril Arica-La Paz; no haber dado facilidades adecuadas en los puertos chilenos y por el uso de las aguas de los ríos Silala y Lauca, etc. Doce de los trece países que intervinieron en el debate se manifestaron a favor de la postura chilena en el sentido de que estos temas debían discutirse en un diálogo bilateral entre las partes.

\subsubsection{La 42 a Asamblea General de la OEA en Cochabamba}

El fracaso en El Salvador en nada menguó los esfuerzos bolivianos por obtener en su favor un pronunciamiento del organismo regional, que en los últimos años le había sido esquivo.

A tal efecto, el gobierno dio comienzo a un gran esfuerzo diplomático en la región (estableció 27 contactos bilaterales) para conquistarse la simpatía hacia su "causa marítima», que asimiló a la reivindicación de las Islas Malvinas por Argentina, tema que estaba de plena actualidad y que por cierto no se asemejaba en absoluto al caso de Bolivia puesto que en el contencioso entre Argentina y el Reino Unido no hay tratados de por medio (posteriormente mencionaría el caso del Canal de Panamá). Al mismo tiempo, en esa campaña acuñó la frase de que "Chile era un mal vecino" y estaba embarcado en una carrera armamentista que ponía en peligro la estabilidad regional.

Según fuentes bolivianas el gobierno del Presidente Morales estaba convencido de que cuando se presentara nuevamente al foro regional, en Cochabamba, un informe sobre el tema marítimo, las expectativas de éxito eran tan propicias como lo habían sido en la Asamblea General de 1979, en La Paz.

El primer indicio de que esta campaña de concientización regional iba por mal camino se produjo poco antes de Cochabamba, durante una visita del Presidente Morales a Colombia, cuyo gobierno en la Asamblea General celebrada en Washington en 1983 se había manifestado dispuesto a mediar entre los dos países para superar las dificultades que los separaban. La posterior 
JaIme Lagos Erazo • Las aspiraciones marítimas de Bolivia...

gestión mediadora colombiana no tuvo ningún resultado.

En Bolivia se anunció que el 15 de marzo, en conversaciones con el Presidente Morales, el Presidente Juan Manuel Santos había apoyado la «causa marítima boliviana como un problema histórico que debe resolverse» e incluso había ofrecido nuevamente mediar en ella. De inmediato, la Cancillería de Bogotá precisó que en esa ocasión el Presidente Santos le había manifestado a Morales que «este es un tema bilateral, que debía ser abordado a través del diálogo, de manera práctica y evitando las instancias internacionales».Difícil articular una advertencia más nítida.

La misma tónica se repitió en Cochabamba, reunión que fue seguida con expectación en nuestra región y fue precedida por un evento popular contrario a Chile (una verdadera «encerrona» para utilizar un gráfico término popular) al cual nuestro Canciller Moreno no asistió.

Después vendría la inauguración oficial de la Asamblea. Una vez expuestas las posturas de ambos cancilleres en el plenario, casi todos los Estados que intervinieron en el debate $(19$, con la excepción de Nicaragua) «valoraron el clima de respeto y ofrecieron su ayuda en el logro de las vías de diálogo, si bien remarcaron que este es un tema de índole bilateral».

El debate se había iniciado con un agresivo discurso del canciller Choquehuanca quien se refirió primero a los antecedentes históricos de la reclamación marítima boliviana por la pérdida de territorio tras una «ignominiosa guerra que Bolivia nunca buscó y planificó», repitiendo las consabidas críticas de que el Tratado de 1904 fue impuesto por la fuerza, insistiendo luego en que los tratados son revisables y que el Tratado de 1904 «insulta a Bolivia» y no es cumplido por Chile. Sobre el particular, abundó en consideraciones tales como que «la imposición de Chile de un régimen de libre tránsito que no se cumple, aísla a mi país de la economía y el comercio» y que en «las actuales fórmulas de funcionamiento de los puertos chilenos... hay inaceptable ingerencia sobre la carga que entra y sale del país».

Finalizó su discurso emplazando a Chile «ya que sus palabras...son sólo eso, palabras vacías, que sólo buscan dilatar y distraer», que Bolivia exigía que nuestro país «renegociara el Tratado de 1904». Este era el «as» bajo la manga que se guardaba el gobierno boliviano y que luego el Presidente Morales amplió con una demanda aún más provocadora.

Con gran serenidad a la vez que firmeza, nuestro Canciller respondió a estas provocaciones refutando primero las sesgadas interpretaciones bolivianas sobre las causas de la Guerra del Pacífico y luego entregando los antecedentes históricos que rodearon la suscripción del Tratado de 1904. Aludió luego el hecho de que a lo largo de su historia, Chile había demostrado estar abierto a la búsqueda de fórmulas que permitan mejorar el acceso al mar de Bolivia y que en el último siglo habían 
tenido lugar varias conversaciones y negociaciones diplomática para tratar de satisfacer esa aspiración. Seguidamente, se refirió a las múltiples ocasiones en que sus principales autoridades se habían reunido para concordar medidas concretas, útiles y factibles en beneficio de ambos países, las que identificó detalladamente para finalizar expresando que en 2010, un $60 \%$ del total del comercio de Bolivia con países no limítrofes había circulado a través de puertos chilenos.

En la misma oportunidad, el canciller chileno volvió a desconocer de la disposición de la Constitución boliviana de 2009 y reiteró que pese a las palabras de desconfianza que había escuchado, Chile se encontraba siempre disponible para continuar con Bolivia un camino de cooperación y diálogo que debía «sustentarse en el respeto mutuo y en la vigencia y pleno reconocimiento del Tratado de Paz y Amistad de 1904 y sus instrumentos complementarios, sobre el cual hemos edificado con Bolivia más de un siglo de paz, estabilidad e integración».

Al finalizar este debate, en una corta improvisación el canciller Choquehuanca insistió en que le hubiera gustado escuchar de su interlocutor una palabra clara y concreta sobre la renegociación del Tratado de 1904 replicando nuestro canciller que «era un poco liviano... pretender que le den una respuesta seria y apresurada» reiterando que "Chile es un país que está establecido en sus límites desde hace muchísimos años» y que no va a cambiar.
Finalizada la Asamblea General de la OEA en la cual Bolivia no logró obtener que se aprobara una resolución, la que ni siquiera presentó ante el clima adverso que percibió, el Presidente Morales salió nuevamente a la palestra para formular una declaración en una conferencia de prensa que causaría una mayor tormenta política. Al inaugurar la Asamblea ya había dicho que todos los tratados son revisables, pero esta vez, en tono totalmente sorprendente y aparentemente sin mayor reflexión dijo que el «Tratado de Paz y Amistad firmado en 1904 con Chile está muerto». Reconoció eso sí que él no era jurista ni conocía los derechos internacionales "pero puedo entender que este Tratado ya está muerto, ese tratado no está vigente para mí, porque Chile ha incumplido el Tratado (se refirió en particular a la privatización del puerto de Arica)» agregando que cuando un acuerdo no se cumple, «ese acuerdo ya no sirve» y pidió a Chile imitar a Estados Unidos que en 1977 devolvió a Panamá el canal transoceánico. Sobre el particular, se interrogó entonces ¿por qué Chile no puede devolver el mar a Bolivia?

De inmediato, en declaraciones periodísticas el canciller Moreno pidió al Presidente boliviano "hablar menos» a través de la prensa y buscar soluciones en conjunto, acotando que al parecer el Mandatario boliviano quiere que "Chile le regale un pedazo de su territorio, cuando no hay un solo ejemplo en la historia de la humanidad en que un país haya regalado una parte de su territorio». 
JaIme Lagos Erazo • Las aspiraciones marítimas de Bolivia...

Agregó además una reflexión, a mi juicio muy pertinente, en el sentido de que es difícil «seguir al Presidente Morales. Primero dijo que el tratado no se cumplía, luego que lo quería renegociar, ahora dice que no existe». Esa frase resume a mí entender la grave contradicción que encierra la actual posición boliviana después de Cochabamba, ya que abre una seria incógnita sobre el futuro de las relaciones entre Chile y Bolivia. Por ello, nos preguntamos si fue quizá una frase dicha al calor de una estrepitosa derrota como la sufrida en Cochabamba o implica que Bolivia intentará ahora judicializar el tema marítimo, para solicitar la revisión o nulidad del Tratado de 1904, teniendo presente, como telón de fondo, la categórica advertencia realizada poco después en Antofagasta por el Presidente Piñera de que "Bolivia debe comprender que los tratados y los acuerdos son para cumplirlos y, en consecuencia Chile hará respetar y respetará siempre el Tratado de 1904», descartando con ello todo intento de renegociarlo como lo había solicitado Bolivia.

El 14 de junio la cancillería chilena emitió un comunicado en que declara que «Chile ha tomado nota de las Declaraciones del Presidente de Bolivia, Evo Morales...expresando que las mismas carecen de sustento y efecto jurídico». Esa declaración, convertida luego en una nota de protesta y entregada al representante boliviano en Santiago, añadía que "ante las expresiones inusuales respecto de la «muerte» de un Tratado internacional que fija los límites entre ambos países, y la afirmación de que no está siendo cumplido, el Gobierno de Chile debe manifestar su malestar y protesta, ya que esas palabras no se condicen con la observancia de las normas y principios básicos del Derecho Internacional con el respeto de lo pactado en el Tratado de 1904».

De más está decir que las palabras del errático Primer Mandatario boliviano causaron indignación en casi todo el espectro político chileno, inclusive en algunos sectores que miran con alguna simpatía la aspiración marítima boliviana. Hubo protestas de numerosos parlamentarios, entre ellos de varios miembros de las Comisiones de Relaciones Exteriores de ambas Cámaras.

En la propia Bolivia hubo severas críticas inclusive de personeros destacados de la diplomacia boliviana como el ex canciller Manfredo Kempff, quien luego de calificar de derrota la ofensiva diplomática boliviana en la cumbre de Cochabamba, señaló que «si Bolivia quiere revisar un tratado internacional tienen que estar de acuerdo las dos o más partes suscriptoras. Si no están de acuerdo las partes, ya no se trata de revisión sino denuncia, que es un asunto muy grave».

No faltaron algunos comentarios sarcásticos en el sentido de que si el Tratado de Paz y Amistad de 1904 está muerto, Bolivia se encuentra con Chile en una situación pre-bélica, aventura en la cual tiene muy pocos amigos confiables.

Nosotros también nos preguntamos, si el Tratado no existe y en consecuencia 
no solo no hay límites ni una situación de paz entre ambos Estados, ¿en qué instrumentos se basarán de ahora en adelante las libertades de tránsito que contempla? Como puede verse, si se concreta la amenaza boliviana se crearía una situación totalmente desconocida en el plano de las relaciones internacionales.

Pese a estas fundadas críticas internas, un editorial del diario «La $\mathrm{Ra}$ zón», de 15 junio, trató de justificar el proceder boliviano atribuyéndolo a su «estrategia marítima», puntualizando que « no se trata de gestos heroicos para recuperar la cualidad marítima perdida con la guerra de 1879 , pero sí de una acumulación de gestos( se refería también a la posterior visita de Morales a La Haya) que en las relaciones internacionales tienen una importancia nada desdeñable, sobre todo cuando los objetivos son claros. Ojala que este sea el caso». Nos quedamos por cierto con esta última duda.

Para mayor confusión, justificando los insólitos dichos de su Presidente, el vicecanciller boliviano Juan Carlos Alurralde, uno de los actuales "halcones» de la política exterior paceña, insistió en que Chile tenía que renegociar el Tratado de 1904 porque la nueva Constitución boliviana así lo establece. El propio ex canciller Kempff le replicó con una argumentación implacable señalando ¿qué le importa a Chile que la Constitución Plurinacional ponga los plazos que le dé la gana para renegociar tratados que le parezcan contrarios al interés nacional? Con esa lógica cada país podría incluir en su Carta Magna todas sus aspiraciones reivindicatorias y ¿serían ellas de cumplimiento obligado para otras naciones?

En resumen, para Bolivia la Asamblea de la OEA de Cochabamba fue un rotundo fracaso precisamente porque los objetivos que se había planteado su diplomacia para ese encuentro regional estuvieron muy lejos de cumplirse. No obstante el despliegue de recursos efectistas, el intenso «lobby» diplomático, el apelar a factores emocionales y el hecho de que se celebró en su territorio, contrariamente a sus deseos Bolivia no obtuvo respaldo alguno para que el tema se resolviera en el plano multilateral propiciándose más bien el diálogo bilateral.

Como muy bien dijo el canciller Moreno «hemos ido despejando el camino. Han pasado 33 años desde que se dictó una resolución en la OEA (la de 1979) y se ha producido una madurez para entender que estos son problemas de dos pueblos, que deben resueltos por esos pueblos».

Chile obtuvo así un importante triunfo diplomático en un órgano multilateral de significativa importancia en nuestra región. Todo ello sin perjuicio de que con su tradicional ambigüedad, después de Cochabamba Morales no ha cerrado completamente la vía de proseguir el diálogo bilateral con Chile, como lo expresó en una entrevista a la revista «Qué Pasa».

Entretanto, Bolivia, aquejada por serios problemas internos, sigue sin responder a la nota de protesta que se 
le entregó el 14 de junio. Tal vez allí encontremos alguna respuesta al escurridizo camino que su impredecible Jefe de Estado pretende ahora seguir para materializar su «estrategia marítima».

\section{PARTE TERCERA}

\section{JUDICIALIZACIÓN DEL TEMA MARÍTIMO}

\subsection{Introducción}

Desde que asumió el Presidente Piñera, el tratamiento del tema por el gobierno del país de Altiplano aparece como el llamado «cuento del lobo»: no se sabe si viene o no.

Recordemos nuevamente que ya en su discurso de marzo del 2011, el Primer Mandatario boliviano había anunciado que recurriría sea a los organismos o a los tribunales internacionales para obtener la reintegración marítima, para lo cual se planificaron las acciones que identificamos. ${ }^{8}$

Antes de la cumbre de Cochabamba algunos órganos de la prensa boliviana y varios ex cancilleres del país vecino habían desaconsejado al gobierno de Morales de conducir la reivindicación marítima boliviana a través de los tribunales internacionales.

Todas estas advertencias cayeron en el vacío y al celebrar con gran solemnidad el 23 de marzo recién pasado el Día del Mar, el gobierno creó

8 Ver página 10. grandes expectativas de que antes de la cita de Cochabamba formularía importantes anuncios relativos a los avances logrados en la preparación de una demanda judicial contra Chile ante la Corte Internacional de Justicia de La Haya. Para la gran sorpresa de todos, Morales anunció entonces que este era un tema serio que requería de mayor preparación.

Después de Cochabamba el Jefe de Estado boliviano profundizaría sobre las razones de este retraso, confirmando que Bolivia continuaría impulsando la demanda contra Chile, aunque nuevamente admitió que tardaría algún tiempo. Ello seguramente fue para responder a las conjeturas periodísticas del momento en el sentido de que Bolivia estaba perdiendo interés en esta iniciativa e incluso había desechado la opción, mencionando varios signos premonitorios. Entre estos se mencionaron las opiniones del ex canciller boliviano Armando Loayza quien fuera de aludir a las dificultades y complejidades de un paso de tal naturaleza opinó que «esa judicialización nos puede llevar a un alejamiento entre Bolivia y Chile, cuando eran positivos los espacios de diálogo que se estaban dando entre ambos países». Por su parte, Ramiro Prudencio, otro destacado historiador boliviano había expresado que «el problema marítimo es un problema político, no es un problema jurídico, no cabe llevar el asunto a un tribunal internacional, porque ahí se ven asuntos netamente jurídicos, como es el caso de Chile y Perú. Acá hay un Tratado...» 
Para refutar estas impresiones, el Presidente Morales agregó que «pensamos que esta demanda internacional iba a ser algo rápido. Revisamos. No había sido sencillo. Perú para ir a su demanda internacional había tardado cuatro o cinco años» y añadió que «hace falta mucho tiempo para reunir la documentación histórica y legal para sustentar la demanda». Al parecer, el entonces embajador peruano en La Paz, Rodríguez Cuadros, el principal gestor de la demanda marítima peruana en La Haya, habría estado involucrado en entregar estos consejos, posiblemente por su propia iniciativa.

Los argumentos que se invocaron desde entonces para llevar el tema de la aspiración marítima boliviana a los tribunales internacionales fueron de una enorme vaguedad. A veces se argumentó que se pediría la revisión del Tratado de 1904 porque fue impuesto por la fuerza y "es injusto"; otras veces el gobierno boliviano manifestó que recurriría a estos tribunales por el uso ilegal de Chile de los recursos hídricos ( Lauca y Silala); en otras oportunidades, que se denunciaría que nuestro país obstaculiza el libre tránsito de Bolivia lo que afecta su desarrollo; que no cumple lo pactado en relación al ferrocarril Arica-La Paz y por la administración privada del puerto de Arica, que se encuentra en manos de un consorcio chilenoperuano( Empresa Portuaria de Arica (EPA), la que considera que debe ser administrado por Bolivia, país que es su principal usuario. Más reciente- mente, como vimos al referirnos a la Asamblea General de la OEA de Cochabamba, la principal denuncia fue el supuesto incumplimiento por Chile de las obligaciones de libre tránsito convenidas en el Tratado de 1904 y acuerdos bilaterales posteriores.

$\mathrm{Al}$ respecto, según la prensa boliviana, el ex canciller Murillo habría coincidido con el Mandatario boliviano en cuanto a que el «incumplimiento de Chile al libre tránsito de mercaderías bolivianas por el puerto de Arica es un elemento jurídico válido para un eventual juicio ante instancias internacionales». Acotó que "ese caso es muy serio porque no hay precedentes de que algún país haya privatizado obligaciones que emanan de un tratado, por eso puede ser uno de los fundamentos para una demanda ante la Corte Internacional de Justicia».

Antes, el ya mencionado ex canciller boliviano Armando Loayza había opinado en forma diametralmente opuesta, señalando que aunque un tribunal internacional determinara que se obstaculiza el libre tránsito no por ello Bolivia recuperaría su cualidad marítima.

Ante la persistente vaguedad, tras la reunión de Cochabamba el canciller Alfredo Moreno respondió en forma socarrona que «después de cien años Bolivia no puede encontrar cuál es la falla del Tratado de 1904», y desmintió tajantemente que Chile estuviera «nervioso» frente a la anunciada demanda y que «no hay ningún fundamento para plantear un caso jurídico». 
JaIme Lagos Erazo • Las aspiraciones marítimas de Bolivia...

Para ratificar su disposición, el paso siguiente que se reservaba el Primer Mandatario boliviano fue realizar, inmediatamente después de la cita de Cochabamba, el día 12 de junio, una visita al Presidente de la Corte Internacional de Justicia.

Pero el gobierno boliviano cometió el faux pas de convertir esta visita de cortesía, que es totalmente habitual cuando un Jefe de Estado extranjero se encuentra en Holanda, en un acto de trascendencia para sus pretensiones diciendo oficialmente que tras una extensa reunión el Presidente de la Corte había escuchado con interés el reclamo marítimo del Presidente Morales e incluso le había sugerido los caminos que debía seguir para plantear la eventual demanda. De inmediato, la Corte emitió un comunicado oficial aclarando que se había tratado de una «corta» visita meramente formal ( «concerniente a los aspectos generales del trabajo de la Corte»). No fue necesario aclarar que la Corte recibe regularmente a los Jefes de Estado en visitas oficiales al tribunal con una ceremonia que comprende el intercambio de discursos y la presencia de los Jueces.

Formuladas estas consideraciones políticas previas, corresponde ahora detenerse a examinar, de la manera más resumida posible, los aspectos legales de esta materia y sus eventuales fundamentos. Se trata de una mera aproximación a un tema jurídico, que requeriría de mayor profundización.

\subsection{Los organismos judiciales internacionales}

\subsubsection{La Corte Permanente de Arbitraje}

Los tribunales internacionales que podrían eventualmente utilizarse para canalizar la aspiración boliviana son primeramente la Corte Permanente de Arbitraje de La Haya (establecida básicamente en 1907), que es el órgano convenido por ambas partes para resolver las controversias que deriven de la aplicación e inteligencia del Tratado de 1904; el otro sería la Corte Internacional de Justicia, órgano totalmente distinto, objetivo prioritario para Bolivia.

El acceso a la jurisdicción de la Corte Permanente de Arbitraje, que simplemente ofrece a las partes una lista de árbitros, está asegurado porque ya está convenido que le corresponde: "pronunciarse en todas las cuestiones que llegasen a suscitarse con motivo de la inteligencia o ejecución de dicho Pacto» (Protocolo Complementario de 1907 al Tratado de 1904, para sustituir al Emperador de Alemania convenido en ese Tratado quien no aceptó el encargo). En ese caso, habrá que seleccionar a los árbitros, concordar en el procedimiento pertinente y si fallará en derecho o en equidad.

\subsubsection{La Corte Internacional de Justicia (CIJ)}

Por lo que se refiere a la Corte Internacional de Justicia, precisamente para 
poder recurrir unilateralmente a este alto tribunal de las Naciones Unidas el año pasado Bolivia ratificó el Pacto de Bogotá de 1948 sobre Solución de Controversias que había firmado pero nunca ratificó, manteniendo la reserva que estampó junto a su firma en 1948.

Conforme a esa reserva, objetada de inmediato por Chile, Bolivia ha aceptado la jurisdicción obligatoria de la Corte a condición de que no se aplique su artículo 6 que excluye de su competencia cuando se trate "de un asunto ya resuelto por arreglo de las partes» $\mathrm{O}$ bien, que se halle "regido por acuerdos o tratados en vigencia en la fecha de celebración del presente Pacto». Con esta reserva, Bolivia pretende impedir que nuestro país oponga una excepción preliminar de inadmisibilidad a la eventual demanda o por la falta de jurisdicción de la Corte, ya que el Tratado de 1904 fue firmado con anterioridad.

Cabe preguntarse si la extemporánea reserva boliviana al Pacto de Bogotá (más de 60 años luego de su firma) tiene algún valor para ser considerada admisible o si estamos más bien ante un claro caso de " cosa juzgada»: un tratado concluido varios años antes del Pacto de Bogotá y ya resuelto por arreglo de las partes.

Esa reserva boliviana atañe al referido artículo 6 de este instrumento que establece que «los procedimientos pacíficos pueden también aplicarse a las controversias emergentes de asuntos resueltos por las Partes, cuando dicho arreglo afecta intereses vitales de un Estado». Mediante nota de 10 de junio de 2011 Chile planteó una objeción a esa reserva señalando que de conformidad con el derecho internacional dicha objeción impide la entrada en vigor de ese Tratado (el de Bogotá) entre Chile y Bolivia.

En consecuencia, la CIJ no tiene base de jurisdicción o competencia para conocer la eventual demanda boliviana, lo que seguramente se podría alegar como una "objeción preliminar» tan pronto esta se presente. Así podría concluir para Bolivia un nuevo intento para llevar esta cuestión a los foros internacionales, esta vez a un tribunal judicial, lo que sepultaría para siempre sus aspiraciones.

La hipotética demanda ante la CIJ ofrece además otros serios obstáculos para conocerla desde el punto de vista de la competencia y la jurisdicción. El art. 31 del Pacto de Bogotá efectivamente obliga a sus partes a resolver por vía jurisdiccional (procedimiento judicial) todas «las controversias de orden jurídico que surjan entre ellas», una vez agotados otros medios de solución de controversias.

Al respecto, cabe preguntarse si se agotaron esos otros métodos de solución y si puede considerarse que estamos en presencia «de una controversia de orden jurídico", a la luz de lo que estipula el artículo 36 del Estatuto de la CIJ. El citado artículo señala que las « controversias de orden jurídico» versan, inter alia, sobre: a) la interpretación de un Tratado; b) cualquiera cuestión de Derecho Internacional, c) la existencia de todo hecho que, si fuere establecido, 
constituiría la violación de una obligación internacional...

Sobre el particular ¿existe algún fundamento para sostener que existe un diferendo jurídico actual entre Bolivia y Chile? Para responder a esta pregunta habrá que examinar los argumentos que hipotéticamente podría invocar Bolivia, conforme a las repetidas afirmaciones de sus gobernantes en distintos periodos y reiterados últimamente.

\subsubsection{Fundamentos de una eventual demanda}

a. A la luz del pasado histórico y jurídico cabe preguntarse si tiene algún asidero legal invocar que el Tratado de 1904 fue «impuesto por la fuerza», que es «injusto» y que está «incumplido», como lo sostiene Bolivia para pedir su revisión tras más de 100 años de haberlo firmado y cumplido.

Ciertamente será imposible probar su ilicitud ante los tribunales internacionales ya que su revisión pugna contra un principio básico del derecho internacional: la intangibilidad de los tratados de límites salvo por consentimiento de las partes, como ya acaeció cuando en 1920 recurrió ante la Sociedad de las Naciones, aunque este era un organismo político.

De acuerdo con los antecedentes históricos, es evidente que no fue impuesto por la fuerza. Desde luego, en la práctica internacional es muy raro que un tratado de paz sea firmado tantos años después del cese de las hostilidades toda vez que comúnmente apenas terminado el conflicto bélico el vencedor impone duras condiciones al vencido. Aun así, el tema del recurso a la guerra ha sido ampliamente discutido en la doctrina y la práctica de los Estados. Al menos hasta 1914 (Primera Guerra Mundial) el jus ad bellum no contemplaba ninguna limitación al derecho a recurrir a la fuerza. Desde luego, cuando estalló la Guerra del Pacífico en 1879 era la práctica normal aceptada en las relaciones entre los Estados y, por tanto, los tratados que le ponían término eran plenamente lícitos. En dos fallos trascendentales de la época, la Corte Permanente de Justicia Internacional (los casos zonas francas (Francia c. Suiza) y Wimbledon (Francia c. Alemania) dicho Tribunal, antecesor de la actual CIJ dio aplicación a tratados que habían sido impuestos por la fuerza por el vencedor. Por otra parte, en una de sus sentencias más recientes (13 de diciembre de 2007), la actual Corte en un fallo relativo a las observaciones preliminares en el caso entre Nicaragua y Colombia por el dominio territorial y marítimo en islas del Caribe se opuso de manera categórica a aceptar los argumentos invocados por Managua para solicitar la nulidad del tratado Esguerra-Bárcenas de 1938, celebrado por Nicaragua, bajo ocupación norteamericana, y Colombia.

La doctrina coincide además en que el derecho internacional clásico, que autorizaba el uso de la fuerza, no podía rehusar la validez de esos tratados (impuestos por la fuerza), por una actividad que se consideraba normal y lícita. 
Después de la Primera Guerra Mundial se suscribieron varios pactos que restringieron el recurso a la guerra (el Pacto de la SDN y el Pacto BriandKellogg), pero ello no impidió que estallara la Segunda Guerra Mundial. Las Cartas de las Naciones Unidas y de la OEA y el Pacto de Bogotá condenan el uso de la fuerza, lo que no ha impedido que después de 1945 se hayan producido varios conflictos bélicos (inclusive entre el Perú y Ecuador en 1941, 1981 y 1995, que acarrearon pérdidas territoriales al Ecuador).

Por lo tanto, este argumento boliviano no tiene mayor destino pues incluso la práctica más reciente (que por cierto no rige a un Tratado suscrito el siglo pasado) tolera el uso de la fuerza, aunque no sea en defensa propia.

De otro lado, Bolivia argumenta que el Tratado de 1904 debe ser revisado por ser injusto e impuesto por la fuerza, como lo establece la Constitución boliviana de 2009 y por ser contrario a esta, que postula el derecho irrenunciable e imprescriptible de una salida soberana al mar.

Ese predicamento ciertamente vulnera un principio básico del derecho internacional contemporáneo, la preeminencia del derecho internacional sobre el derecho interno. La Convención de Viena sobre el Derecho de los Tratados, de 1969, codificó este principio en su art. 27 al señalar que «una parte no podrá invocar las disposiciones de su derecho interno como justificación del incumplimiento de un tratado». El no cumplimiento de esta norma fundamen- tal pone en tela de juicio la responsabilidad internacional de los Estados.

Demás está decir que si Bolivia, cualquiera que sea el fundamento invocado, intenta la revisión del Tratado de 1904, la pretensión es inadmisible bajo el derecho internacional contemporáneo que se ciñe al principio fundamental del "pacta sund servanda», esto es, los tratados obligan y deben ser cumplidos de buena fe, principio universal recogido por la propia Convención de Viena.

Obviamente, ningún tribunal internacional jurídico y menos la CIJ aceptará la revisión de un tratado internacional, sobre todo de fronteras, válidamente celebrado, salvo por consentimiento entre ambas partes.

Sin embargo, la Convención de Viena sobre el Derecho de los Tratados contiene algunas disposiciones que han sido utilizadas o podrían invocarse por Bolivia para solicitar la revisión e incluso la anulación del Tratado de 1904.

En su art.62 la Convención de Viena prevé lo que se denomina la cláusula «rebus sic stantibus», o cambio fundamental en las circunstancias que podrían dar motivo para poner fin a un tratado o retirarse de él. Esta causal puede invocarse en dos situaciones claramente definidas, pero excluye de manera específica los casos de tratados de fronteras. Con ello se quiere mantener un principio básico del derecho internacional que es el carácter permanente y estable de las fronteras, principio reconocido en varios fallos de la CIJ, en particular en el caso del Templo de Preah Vihear, de 1962. 
JaIme Lagos Erazo • Las aspiraciones marítimas de Bolivia...

Otra causal de terminación o suspensión de un Tratado es su « violación grave» y entre ellas «la violación de una disposición esencial para la consecución del objeto o el fin del tratado". Es casi superfluo decir que Bolivia no tiene base alguna para acusar a Chile de violar el Tratado de 1904.

Por lo que atañe a la nulidad de los tratados, la misma Convención de Viena establece el principio de su irretroactividad, esto es, que se aplica únicamente a los Tratados concluidos por los Estados después de su entrada en vigor. De modo que su validez se juzga por las condiciones existentes en el momento en que fue pactado (1904).

Cabe preguntarse qué otros argumentos bolivianos podrían teóricamente calificar para ser considerados como una «controversia internacional» y que Chile está violando una obligación internacional a la luz del derecho internacional. A ellos nos referimos a continuación.

\section{b. Celebración del Tratado de 1904}

Sin reiterar los argumentos sobre los orígenes de la Guerra del Pacífico, cabe recordar que, como Chile lo ha sostenido en innumerables oportunidades, la acusación de que dicho "Tratado fue injusto e impuesto por la fuerza» es una distorsión histórica, puesto que fue largamente estudiado y negociado con los gobernantes bolivianos de la época, suscrito veinte años después del término de la Guerra del Pacífico y 24 años luego que Bolivia abandonara el campo de batalla (1880), sin que hubiera ningún acoso militar chileno, como lo ha recordado una vez más el canciller Moreno en su intervención en Cochabamba, añadiendo que posteriormente, el Presidente boliviano Montes, uno de sus principales gestores, fue elegido dos veces a esa importante función. Menos se recuerda que la Memoria que presentó en 1905 el ministro de relaciones exteriores Claudio Pinilla al Congreso de su país referente a la aprobación parlamentaria respectiva en la que dice que el Tratado de 1904 fue precedido «de un largo y tranquilo debate» con el Poder Ejecutivo y que el «Gobierno...se halla íntimamente convencido de que si bien dicho Tratado no satisface en toda su amplitud las patrióticas aspiraciones del pueblo boliviano viene, en todo, a llenar una necesidad harto sentida por el país, cual es la de consolidar nuestra autonomía económica e impulsar el progreso de la Nación sin las trabas que ofrece una situación incierta e indefinida».

A luz de estos antecedentes históricos oficiales, difícilmente podría aún sostenerse con algún asidero legal que el Tratado de 1904 fue «impuesto» por la fuerza y es «injusto».

\section{c. Facilidades de tránsito}

Por el Tratado de 1904, Chile reconoció a favor de Bolivia el más amplio y libre derecho de tránsito por su territorio y el uso de todos los puertos chilenos en el Pacífico y en 1937 se suscribió una Convención de Tránsito Es más, por el Tratado de 1904 Chile se comprometió a construir a sus expensas un ferrocarril para unir el puerto de Arica con el 
Alto La Paz (inaugurado en 1913) y traspasar la sección boliviana 15 años después de terminado (1928).

El FCAL (Ferrocarril Arica-La Paz) tiene más de 450 kilómetros, 241 de los cuales constituyen el tramo entregado a Bolivia.

Entre 1997 y 2005 el tramo chileno fue administrado por un consorcio privado a cargo de un empresario boliviano, hasta que dicha empresa cayó en quiebra por diversas razones (caída de puentes, crecida del río Lluta, desvío de carga a camiones). Chile ha invertido 58 millones de dólares para rehabilitar la vía, inutilizada desde 2005. En noviembre de 2011 se anunció que la explotación del Ferrocarril, cuyas obras deben concluir en julio de 2012, se entregaría a la Empresa Portuaria de Arica (EPA) y que la licitación de la operación a terceros tendría lugar en 2013. Bolivia reclamó de inmediato, manifestando su interés en administrarlo.

Por otra parte, Chile reconoce y garantiza el mencionado libre tránsito a través de su territorio y puertos mayores...y «comprende toda clase de carga y en todo tiempo y sin excepción alguna», $y$ autoriza a Bolivia para mantener Agentes y Almacenes Aduaneros en los puertos chilenos de Arica y Antofagasta (más recientemente se ha incorporado a Iquique), que abarcan parte importante de las importación y exportaciones bolivianas.

A esas facilidades portuarias se unen otras, como el acuerdo de 1957 que dio origen al oleoducto Sica-Sica- Arica y la futura puesta en operación del Fe- rrocarril Arica a La Paz, para lo cual Chile tendrá que invertir 58 millones de dólares adicionales. Chile también está vinculado a Bolivia por vía ferroviaria entre Antofagasta y Oruro.

Existe además una amplia red caminera que se está mejorando. El MOP tiene un plan de inversión vial y fronteriza con Bolivia por 338 millones de dólares. A ello hay que agregar dos modernos complejos fronterizos en Chungará y Visviri, la habilitación de un puerto seco para Bolivia y obras por valor de 80 millones de dólares en el puerto de Arica para potenciar el comercio con dicha nación.

En resumen, pocas naciones sin litoral en el mundo (hoy más de 40) pueden exhibir una más amplia red de acceso al mar que estas facilidades otorgadas por Chile a su tránsito comercial y de pasajeros.

En 1965, bajo el patrocinio de las Naciones Unidas, se suscribió una Convención sobre el Comercio de Tránsito de Países Sin Litoral que Bolivia no ha ratificado porque las facilidades de comercio que contempla son muy inferiores a las que recibe de Chile.

Bolivia tampoco ha manifestado mayor interés en aprovechar las ventajas que le ofrece la Convención de las Naciones Unidas sobre el Derecho del Mar, de 1982, que permite que Perú y Chile inviten a Bolivia, como Estado sin Litoral, a participar sobre una base equitativa «en la explotación de una parte apropiada del excedente de recursos vivos de las zonas económicas exclusi- 
vas» que tienen como Estados ribereños frente a las costas de Tacna y Arica.

Ante la falsa acusación de que Bolivia es un país enclaustrado cabe mencionar que, además de Chile, mantiene varias conexiones ferroviarias y zonas francas con Argentina y con Brasil, además de conexiones por vía fluvial. Estará además unida a los corredores bioceánicos que se proyectan entre los puertos del Atlántico y el Pacífico.

Además, Perú dispone de vías terrestres y ferroviarias en particular con los puertos de Ilo (el llamado proyecto « Boliviamar») y Matarani, aunque estos puertos peruanos difícilmente podrán reemplazar a Arica y Antofagasta para el tránsito de sus productos debido a la mayor distancia, la carencia de infraestructura y la falta por ahora de adecuados medios de comunicación.

Para finalizar, este capítulo, cabe señalar que algunos autores bolivianos que han estudiado más a fondo la cuestión de la pretendida «judicialización» de la demanda boliviana han llegado a iguales conclusiones que las antes indicadas.

Marcelo Ostria Trigo, conocido analista y ex asesor presidencial, en una reciente crónica publicada el 31 de marzo pasado en el portal electrónico «Hoy Bolivia Com» examina destalladamente todas las opciones que se le ofrecen a su país en el marco judicial. En uno de sus capítulos, tras estudiar «el camino de nulidad del Tratado de 1904 ante organismos internacionales» afirma que «la revisión del Tratado de 1904, por decisión o fallo de una instancia internacional, por ahora está cerrada». Así pues, solo quedarían dos caminos: 1. Una negociación para revisar de mutuo acuerdo con Chile el Tratado de 1904, y 2. Una negociación que, sin modificar los términos de este Tratado, considere una solución práctica para ceder a Bolivia una franja territorial que la vincule con el Océano Pacífico.

Esta una tarea pendiente de nuestra diplomacia, teniendo presente que el derecho internacional está de su lado y que la intangibilidad del Tratado de 1904 es la viga maestra sobre la cual reposa el futuro de sus relaciones con Bolivia. Sobre esas eventuales propuestas y el rol que juega Perú en esta ecuación trilateral, reservamos nuestras opiniones para un próximo artículo de opinión. 